\title{
Altered gene expression profile in a rat model of gentamicin-induced ototoxicity and nephrotoxicity, and the potential role of upregulated Ifi44 expression
}

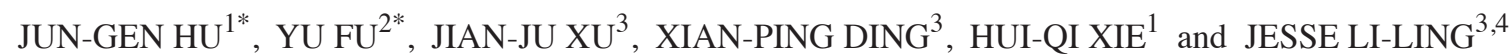 \\ ${ }^{1}$ Laboratory of Stem Cell and Tissue Engineering, Regenerative Medicine Research Center, West China Hospital, \\ Sichuan University, Chengdu, Sichuan 610041; ${ }^{2}$ Department of Hematology, Shengjing Hospital Affiliated to \\ China Medical University, Shenyang, Liaoning $110003 ;{ }^{3}$ Institute of Genetic Medicine, School of Life Science, \\ Sichuan University, Chengdu, Sichuan 610041; ${ }^{4}$ Jinxin Research Institute of Reproductive Medicine and \\ Genetics, Jinjiang Women and Children's Health Care Hospital, Chengdu, Sichuan 610020, P.R. China
}

Received April 18, 2016; Accepted March 30, 2017

DOI: $10.3892 / \mathrm{mmr} .2017 .7150$

\begin{abstract}
As demonstrated by Alport syndrome, the co-occurrence of auditory and urinary system malformations, and gentamicin-induced ototoxicity and nephrotoxicity, the ears and kidneys potentially share certain molecular pathways. In the present study, microarray chips were used to analyze the changes in the gene expression profile using a rat model of gentamicin-induced ototoxicity and nephrotoxicity, using rat liver tissue as a control. A number of genes were identified to exhibit similar expression changes in the rat ears and kidney tissues, among which microtubule-associated protein 44 (Ifi44), was selected for further analysis to validate its expression changes and confirm potential involvement in the inflammation process in the disease model. Ifi44 is a member of the type I interferon-inducible gene family. Reverse transcription-quantitative polymerase chain reaction, western blotting and immunohistochemistry were performed; the results demonstrated that more inflammatory cells were present in cochlear and renal parenchyma in gentamycin-induced rats, and Ifi44 expression was increased in these two organs compared with control rats. Taken together, with its role in lupus nephritis and expression in the inner ear, the results
\end{abstract}

Correspondence to: Professor Hui-Qi Xie, Laboratory of Stem Cell and Tissue Engineering, Regenerative Medicine Research Center, West China Hospital, Sichuan University, 1 Keyuan 4th Road, Wuhou, Chengdu, Sichuan 610041, P.R. China

E-mail: xiehuiqi@scu.edu.cn

Professor Jesse Li-Ling, Institute of Genetic Medicine, School of Life Science, Sichuan University, Teaching Building 3, 17, Section 3, Renmin South Road, Wuhou, Chengdu, Sichuan 610041, P.R. China E-mail: jliling@scu.edu.cn

*Contributed equally

Key words: microtubule-associated protein 44 gene, gene expression profile, gentamicin, nephrotoxicity, ototoxicity suggested that Ifi44 is potentially involved in the inflammation associated with gentamicin-induced ototoxicity and nephrotoxicity. The approach of the current study has also provided a strategy for delineating common pathways shared by organs involved in specific diseases.

\section{Introduction}

The ear and kidney are likely to share certain molecular pathways, which is demonstrated by the variety of congenital syndromes that involve malformations in both the auditory and urinary system, including Branchio-oto-renal syndrome [Online Mendelian Inheritance in Man (OMIM) entry 113650; characterized by co-occurrence of branchial, ear, and renal anomalies], Alport syndrome (OMIM entry 301050; characterized by hematuria, renal failure and hearing impairment) (1), and aminoglycoside-induced ototoxicity and nephrotoxicity. Our previous study demonstrated that T-box 1, a gene implicated in ear development, is also expressed in embryonic kidney tissues and interacts with homeobox D10 (2).

Gentamicin (GM) is an aminoglycoside antibiotic widely used to treat various types of bacterial infection, particularly those caused by Gram-negative microorganisms. The drug inhibits protein synthesis in the bacteria and alters the permeability of bacterial membrane. Following administration, 90\% of GM retains its structure without being metabolized by the liver, and is excreted by the renal tubules, particularly the proximal convoluted tubules. However, GM is highly ototoxic and nephrotoxic, but the mechanism is unclear. Research on the ototoxicity of GM demonstrated that there is massive apoptosis of the vestibular hair cells during the course of disease (3). Notably, rats receiving overdosage of GM also exhibited extensive necrosis of the proximal convoluted tubules, and those receiving a clinical dosage of GM still exhibited significant apoptosis without necrosis of the epithelial cells of the proximal convoluted tubules (4).

Aminoglycoside enters cells by endocytosis or ion channel permeation (5-7). Though all cells take up aminoglycoside, 
the majority of them clear the drug (8). However, the kidney and inner ear also retain aminoglycoside, but are susceptible to aminoglycoside-inducible toxicity. The two organs are anatomically unrelated, but they do share common characteristics, including fluid and ion regulation, and protein expression of various ion channels and transporters (9). We hypothesized that certain molecular mechanisms may be associated with the ototoxicity and nephrotoxicity of GM.

GM induces damage by overproduction of reactive oxygen species and inflammation (10). Interferons (IFNs) are important cytokines involved in inflammation (11). Microtubule-associated protein 44 (Ifi44) has been reported to be antiproliferative (12). Ifi44, also termed interferon-inducible protein 44 or p44 as it aggregates to form microtubular structures, is part of the type I IFN-inducible gene family. Its promoter region contains an IFN- $\alpha$ stimulation responsive elements, which can mediate type I IFN-inducible gene pathway. Ifi44 is an inflammatory consensus gene (13). In a glial cell line challenged with neurotoxin candoxin, Ifi44 appears to have an important role in candoxin-induced glial inflammation (14). Thus, Ifi44 may be associated with the inflammation involved in GM-induced ototoxicity and nephrotoxicity.

The current study used microarrays to analyze the gene expression profiles of ear and kidney tissues derived from a rat model for GM-induced ototoxicity and nephrotoxicity. To filter non-specific genes, gene expression profiles of liver tissue from the model animal were used for normalization. Based on the microarray results and hypothesis that Ifi44 may be associated with the inflammation of GM-induced ototoxicity and nephrotoxicity, a series of techniques were performed to investigate the expression of Ifi44.

\section{Materials and methods}

Animal model, group design and sample collection. Wistar rats ( $\mathrm{n}=30 ; 4$ days old), were obtained from Animal Center of China Medical University (Shenyang, China). The animals were housed in stainless steel wire-mesh cages (5 rats per cage) under standard laboratory condition $\left(25^{\circ} \mathrm{C}\right.$, relative humidity $60 \%$, and $12 \mathrm{~h}$ dark-and-light cycle). The animals were allowed free access to water and food.

The rats were randomly divided into the control and GM groups. For the GM group, each rat received a dose of $80 \mathrm{mg} / \mathrm{kg}$ GM via intramuscular injection. For the control group, each animal received an equal volume of normal saline. The injections were administered once a day for 7 days consecutively.

On the 7th day, $300 \mu 1$ blood was collected by cardiac puncture. Blood samples were immediately placed in $1.5 \mathrm{ml}$ centrifuge tubes containing heparin. After centrifugation at 2,000 x g for $10 \mathrm{~min}$, plasma samples were collected and stored at $4^{\circ} \mathrm{C}$. Plasma analysis was conducted within 2 days of collection. A total of 10 rats (randomly 5 per group) were sacrificed by overdose of anesthetic. The kidneys, cochlear tissue and liver were collected. The samples were processed soon after. The study was approved by the ethics committee of Sichuan University (Chengdu, China).

Biochemical analysis. Plasma serum creatinine ( $\mathrm{SCr}$ ) and blood urea nitrogen (BUN) levels were determined with
Serum Creatinine kit (Beijing Leadman Biochemistry Co., Ltd., Beijing, China) and Blood Urea Nitrogen kit (Beijing Leadman Biochemistry Co., Ltd.), respectively, with an AU480 Chemistry system (Beckman Coulter, Inc., Brea, CA, USA) according to manufacturer's instructions.

RNA extraction. Total RNA was isolated from tissue samples with TRIzol reagent (Invitrogen, Thermo Fisher Scientific, Inc., Waltham, MA, USA) following the manufacturers' instructions. Total RNAs were quantified with a Nanodrop spectrophotometer (Thermo Fisher Scientific, Inc., Waltham, MA, USA). Samples of total RNA from ears, kidney and liver of rats from the same group were pooled for subsequent GeneChip analysis. Prior to the analysis, pooled total RNA samples were purified using an RNeasy Total RNA Mini Kit (Qiagen, Inc., Valencia, CA, USA) according to the manufacturer's instructions.

GeneChip analysis. The GeneChip scan was performed with an Affymetrix GeneChip Rat 2302.0 array (Affymetrix; Thermo Fisher Scientific, Inc., Waltham, MA, USA) according to the manufacturer's instructions. Gene expression changes were represented as ratios between the GM and control groups. Gene expression profiles of liver tissue were used for normalization. The difference value of expression ratio between cochlear and liver, or kidney and liver was calculated to determine the change tendency. A ratio $>1$ indicated that the gene expression was upregulated, and vice versa. Selected genes were classified into four categories for further analysis, as follows: Upregulated in cochlear; downregulated in cochlear; upregulated in kidney; and downregulated in kidney. Genes exhibiting similar tendencies were selected.

Histology and immunohistochemistry. Cochlear, kidney and liver tissues from the rats were preserved in $10 \%$ phosphate-buffered formalin. Tissues fixed with neutral formalin were embedded in paraffin and sectioned at $3 \mu \mathrm{m}$. Hematoxylin and eosin (H\&E) staining was performed to observe GM-induced ototoxicity, indicated by loss of cochlear hair cells and inflammation.

To identify Ifi44 protein in the cochlear and kidney, sectioned paraffin-embedded tissue samples were deparaffinized for immunohistochemistry. Slides were incubated with $3 \% \mathrm{H}_{2} \mathrm{O}_{2}$ at room temperature for $10 \mathrm{~min}$ to eliminate endogenous peroxidases, and washed with distilled water and PBS. The slides were then incubated with $5 \%$ goat serum (ZsBio, Beijing, China) at room temperature for $10 \mathrm{~min}$. Primary antibody (rabbit anti-rat-IFI44 primary antibody; GTX32667; 1:100; GeneTex, Inc., Irvine, CA, USA.) incubation was performed at $37^{\circ} \mathrm{C}$ for $2 \mathrm{~h}$. PBS was used as blank control for primary antibody incubation. After washing with PBS, biotinylated goat anti-rabbit IgG secondary antibody (ZB-2010; 1:200; ZsBio) incubation was performed at $37^{\circ} \mathrm{C}$ for $30 \mathrm{~min}$. The slides were washed with PBS and incubated with HRP-streptavidin (ZB-2404; 1:500; ZsBio) working buffer at $37^{\circ} \mathrm{C}$ for $30 \mathrm{~min}$. The slides were washed with PBS and incubated with diaminobenzidine at room temperature for 10 min, followed by washing with water and H\&E staining. The sections were imaged with an Eclipse E600 microscope (Nikon Corporation, Tokyo, Japan). 
Table I. Primers for reverse transcript-quantitative polymerase chain reaction.

\begin{tabular}{lll}
\hline Gene & \multicolumn{1}{c}{ Forward primer (5'-3') } & \multicolumn{1}{c}{ Reverse primer (5'-3') } \\
\hline Ifi44 & AGC CGT ATG GAG ACC TGG & TGA GTG ATG CTG CCC TTG \\
Gapdh & TCA CCA CCA TGG AGA AGG C & GCT AAG CAG TTG GTG GTG CA
\end{tabular}

A

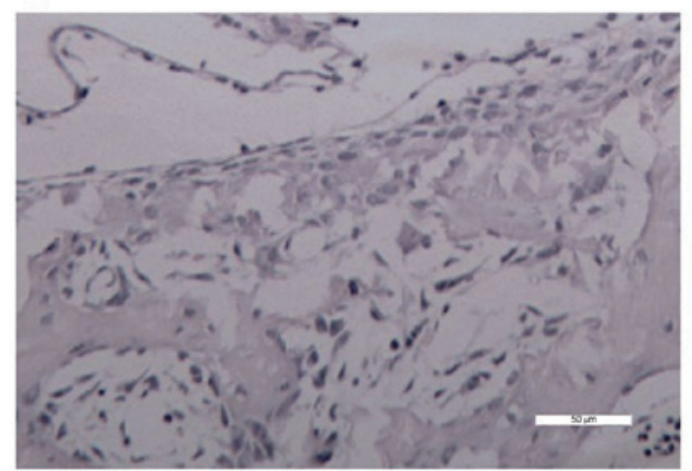

C

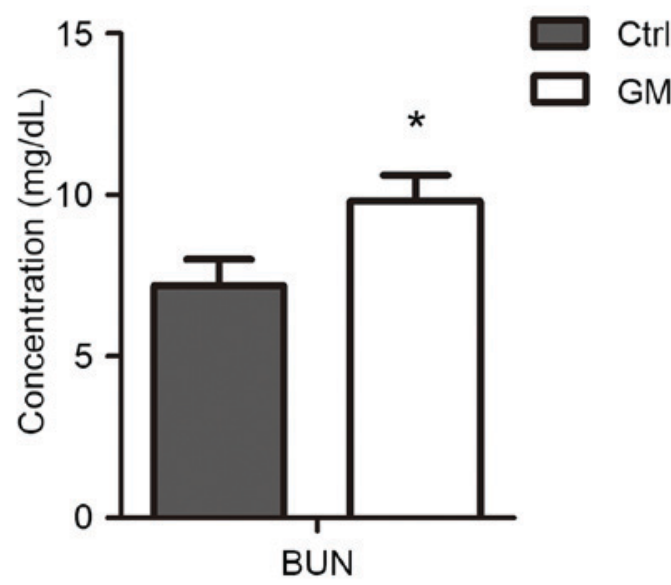

B
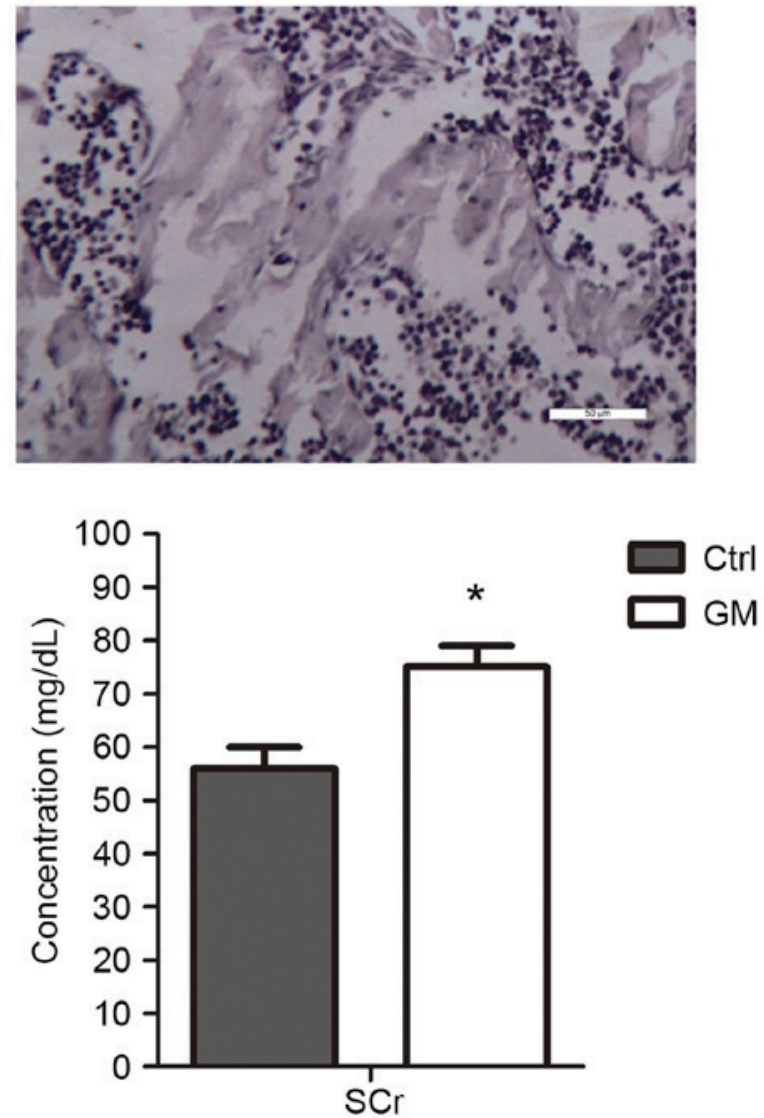

Figure 1. Hematoxylin and eosin staining of cochlear tissue and blood SCr and BUN levels. Compared with (A) the control group, more inflammatory cells can be observed in cochlear tissue from (B) the GM group. (C) Concentration of blood BUN and SCr. In the GM group, both were increased. ( $\mathrm{P}<0.05$ ). Scale bar, $50 \mu \mathrm{m}$. Ctrl, control; GM, gentamicin; BUN, blood-urea-nitrogen; $\mathrm{SCr}$, serum creatinine.

Reverse transcription-quantitative polymerase chain reaction $(R T-q P C R)$. Extracted RNA was converted to cDNA by reverse transcription of $1 \mu \mathrm{g}$ RNA with random primers and AMV reverse transcriptase (Applied Biosystems, Thermo Fisher Scientific, Inc.). The reverse transcription conditions were $42^{\circ} \mathrm{C}$ for $1 \mathrm{~h}$ and $99^{\circ} \mathrm{C}$ for $5 \mathrm{~min}$. Primers (Table I) were designed using Primer 3 software (http://primer3.ut.ee) and synthesized by Genscript Biotech Corporation (Nanjing, China). The reverse transcription and $\mathrm{qPCR}$ were performed out on an $\mathrm{ABI}$ PRISM 7500 Sequence Detection system (Applied Biosystems; Thermo Fisher Scientific, Inc., Waltham, MA, USA). qPCR was performed in a total volume of $20 \mu \mathrm{l}$, with each well containing $10 \mu 1$ SYBR Green PCR Master Mix (Applied Biosystems; Thermo Fisher Scientific, Inc.), $2 \mu \mathrm{l}$ cDNA, and $0.4 \mu \mathrm{M}$ Ifi44 or Gapdh primers. The PCR condition consisted of initial denaturation step at $95^{\circ} \mathrm{C}$ for $30 \mathrm{sec}$, followed by 40 cycles of $95^{\circ} \mathrm{C}$ for $5 \mathrm{sec}$ and $60^{\circ} \mathrm{C}$ for $34 \mathrm{sec}$. The relative level of gene expression was calculated using the $2^{-\Delta \Delta \mathrm{Ct}}$ method (15).
Western blotting. To prepare protein samples for western blotting, prepared tissues (cochlear, kidneys, and livers) were cut into pieces and washed with PBS three times. Tissue pieces were homogenized in RIPA lysis buffer (P0013B; Beyotime Institute of Biotechnology, Shanghai, China) containing PMSF, and centrifuged at $10,000 \mathrm{x}$ g for $10 \mathrm{~min}$ at $4^{\circ} \mathrm{C}$. The supernatant was collected and protein concentration was determined using BCA Protein Assay reagents (Pierce, Thermo Fisher Scientific, Inc.). Protein loading buffer (5X; P0015; Beyotime Institute of Biotechnology) was added into the supernatant, and then boiled for $10 \mathrm{~min}$. The protein samples were stored at $-70^{\circ} \mathrm{C}$ until use. Protein samples were loaded, $100 \mu \mathrm{g}$ for each well, onto a SDS-PAGE gel and transferred to a PVDF membrane (Sigma-Aldrich, Merck KGaA, Darmstadt, Germany). The membrane was then incubated with $5 \%$ nonfat dry milk for $3 \mathrm{~h}$ at room temperature, and then with rabbit anti-rat-IFI44 primary antibody (GTX32667; 1:1,000; GeneTex) and rabbit anti-rat-GAPDH primary 
antibody (GTX100118; 1:1,000; GeneTex) for $2 \mathrm{~h}$ at room temperature. The membrane was washed with $0.1 \%$ TBST for 5 times and incubated with horseradish peroxidase-conjugated goat anti-rabbit antibody (ZB-2301; 1:2,500; ZsBio) as the secondary antibody for $1 \mathrm{~h}$ at room temperature. After final washing with $0.1 \%$ TBST for 5 times, protein bands were detected with an enhance chemiluminescence assay kit (Pierce, Thermo Fisher Scientific, Inc.).

Statistical analysis. All experiments were conducted in triplicate and repeated at least twice. The group mean \pm standard deviations were calculated for each measured parameter. Statistical differences between the groups were evaluated using the Student's t test with SPSS version 16.0 (SPSS, Inc., Chicago, IL, USA). $\mathrm{P}<0.05$ was considered to indicate a statistically significant difference.

\section{Results}

Ototoxicity and nephrotoxicity induced by GM. H\&E staining of cochlear tissue from the rats demonstrated distinct inflammatory invasion in the GM group (Fig. 1A and B). Increased blood $\mathrm{SCr}$ and BUN levels are indicators of kidney dysfunction. In the GM group, there were significant increases in the levels of both indicators compared with the levels in the control group $(\mathrm{P}<0.05$; Fig. $1 \mathrm{C})$.

Morphological changes in the cochlear tissue, as revealed by H\&E staining, along with the biochemical changes in blood, indicated that GM induced ototoxicity and nephrotoxicity in the experimental group rats.

Analysis of GeneChip data. The Affymetrix Rat Genome 230 2.0 microarray contains 31,000 probe sets corresponding to $\sim 24,000$ annotated rat genes and 6,693 expressed sequence tags. As GM predominantly causes damage in the kidney and ear, to explore the similarities in gene expression changes between the kidney and ear, genes significantly altered in the liver tissue from both groups were excluded from further analysis. The genes that were unchanged in the liver tissue between the two groups were classified into four categories: Upregulated in the kidneys; downregulated in the kidneys; upregulated in the cochlear; and downregulated in the cochlear (Tables II-V). Compared with the control group, nine genes exhibited similar expression changes in the kidneys and ears in the GM group (Table VI).

Ifi44 was one of the significantly upregulated genes in cochlear and kidney tissue, but not changed in the liver tissue of the GM group with a ratio of 2.45184 (GM cochlear vs. control cochlear) and 3.2915 (GM kidney vs. control kidney), respectively. As Ifi44 is associated with inflammation processes, further analysis was conducted to verify its expression in the cochlear and kidney tissues.

Changes of Ifi44 gene expression in the kidneys and ears. To verify the changes of Ifi44 expression in GM group rats compared with control rats, RT-qPCR, western blotting and immunohistochemistry were performed. As demonstrated in Figs. 2 and 3, the expression of Ifi44, at the transcriptional and translational levels, was increased in ear and kidney tissue in the GM group rats compared with control group rats.
Table II. Upregulated genes in the kidney.

Difference value

Gene

(kidney ratio-liver ratio)

Abcbla

2.43477

$A b c b 1 a / A b c b 1 b$

17.722

Adfp

2.20688

Afp

2.188205

Areg

2.44116

Bazla

1.08197

Bhlhe41

3.47949

Btg2

2.09308

Clqa

0.94038

C2

1.65742

C3

1.77948

Calcb

1.460037

Ccl4

1.140705

Cdknla

2.64699

Cebpd

1.867527

Cfi

1.13327

Ch25h

1.50461

Chka

2.850202

Cldn4

1.53799

Clecsfo

1.339374

Clrn3

0.98247

Clu

1.17991

Corola

2.17874

Csrnpl

3.07711

1.85086

Cst7

14.43329

Cxcl11

0.80693

Dhx58

1.64244

1.10571

1.983407

1.25444

1.06992

1.9031

1.00979

1.00537

2.675193

2.030199

1.409335

1.030706

0.92643

1.27193

1.20101

1.204013

1.85006

0.50785

2.86349

1.11695

1.27326

1.04459

1.155802

Klhdc5

1.07074 
Table II. Continued.

\begin{tabular}{|c|c|}
\hline Gene & $\begin{array}{c}\text { Difference value } \\
\text { (kidney ratio-liver ratio) }\end{array}$ \\
\hline LOC290595 & 2.58298 \\
\hline LOC679127 & 1.01209 \\
\hline LOC685277 & 1.310726 \\
\hline$L y 6 b$ & 9.520954 \\
\hline Maff & 7.34486 \\
\hline Map7 & 1.05453 \\
\hline$M G C 105649$ & 2.276752 \\
\hline Mobkl1b & 1.7147 \\
\hline$M s 4 a 7$ & 2.84021 \\
\hline Naglt1 & 1.23055 \\
\hline$N r 4 a 3$ & 1.781463 \\
\hline Nrgl & 6.408646 \\
\hline Nupll & 1.326609 \\
\hline Osbpl3 & 1.269767 \\
\hline Parp 14 & 0.89769 \\
\hline Pim3 & 1.714337 \\
\hline Pla2g15 & 1.03518 \\
\hline Plcxd2 & 6.208169 \\
\hline PLEK & 0.86853 \\
\hline Pltp & 1.34507 \\
\hline Ppplr15a & 1.64453 \\
\hline Pspc1 & 1.44648 \\
\hline$P V R$ & 5.07916 \\
\hline Rassf1 & 1.185572 \\
\hline Rell2 & 1.575769 \\
\hline RGD1306820 & 1.081854 \\
\hline RGD1559960/Sult1c2 & 7.78885 \\
\hline Rndl & 1.91742 \\
\hline Rpp25 & 0.88792 \\
\hline$R T 1-E C 2$ & 1.44442 \\
\hline Scin & 1.574135 \\
\hline Serpincl & 4.471142 \\
\hline Shoc2 & 0.88887 \\
\hline Slc13al & 1.359457 \\
\hline$S l c 2 a 2$ & 1.960617 \\
\hline Slc $34 a 2$ & 1.73034 \\
\hline Sppl & 1.538939 \\
\hline Srxn1 & 1.16717 \\
\hline Stat2 & 0.87204 \\
\hline Steapl & 1.203958 \\
\hline Stra6 & 1.740229 \\
\hline Thrsp & 0.90096 \\
\hline Tinag & 5.758012 \\
\hline Tmem140 & 2.3678 \\
\hline$T u b b 2 c$ & 1.560787 \\
\hline Utx & 1.374016 \\
\hline$W d r 43$ & 1.370004 \\
\hline Zbtb10 & 1.09374 \\
\hline
\end{tabular}

Table III. Downregulated genes in the kidney.

\begin{tabular}{|c|c|}
\hline Gene & $\begin{array}{c}\text { Difference value } \\
\text { (kidney ratio-liver ratio) }\end{array}$ \\
\hline Aadac & -0.487787 \\
\hline$A k r l b 7$ & -0.625335 \\
\hline$A l b$ & -0.744701 \\
\hline Apoc2 & -0.52801 \\
\hline Cryab & -0.488116 \\
\hline Dnase1 & -0.756643 \\
\hline E030032D13Rik & -0.649601 \\
\hline$E g f$ & -0.382176 \\
\hline Enpp6 & -0.76638 \\
\hline Hpgd & -0.629649 \\
\hline $\mathrm{Hrg}$ & -0.595822 \\
\hline Inmt & -0.582937 \\
\hline Klklclo & -0.734721 \\
\hline Mylk3 & -1.077123 \\
\hline Ogn & -0.626234 \\
\hline Ppplrla & -0.420662 \\
\hline$R G D 1305645$ & -0.348252 \\
\hline RGD1305679 & -0.491102 \\
\hline $\operatorname{Rgn}$ & -0.46558 \\
\hline Slc22a13 & -0.657262 \\
\hline Slc34al & -0.498645 \\
\hline Slcola6 & -0.733911 \\
\hline Sult1c2 /// Sult1c $2 a$ & -0.397167 \\
\hline
\end{tabular}

These results were consistent with the results of the GeneChip microarray.

\section{Discussion}

By comparing the gene expression profiles, a number of genes were identified that may be specifically involved in GM-induced ototoxicity and nephrotoxicity. Among these, Ifi44 expression was upregulated in cochlear and kidney tissue from GM treated rats. GM is known to induce damage by overproduction of reactive oxygen species and inflammation (10), and IFNs are important cytokines for inflammation (11). Ifit4 has been reported to be antiproliferative (12), and its functions include participation in microtubule formation, promotion of apoptosis, inhibition of proliferation and involvement in autoimmune response. The GeneChip analysis indicated that upregulated Ifi44 expression may be involved in the inflammation associated with GM-induced ototoxicity and nephrotoxicity. Further analysis confirmed that Ifi44 expression was upregulated at the transcriptional and translational levels.

GM tends to accumulate in renal tubular cells (16), which is in keeping with the expression of protein and cation transporters, namely the giant endocytic complex formed by megalin and cubilin present in the proximal tubule. Intracellular accumulation of GM may be a key factor of GM-induced nephrotoxicity. Ifi44 was proposed to interact with intracellular GTP (12). Blocking of GTP-associated 
Table IV. Upregulated genes in the cochlear.

\begin{tabular}{|c|c|}
\hline Gene & $\begin{array}{c}\text { Difference value } \\
\text { (cochlear ratio-liver ratio) }\end{array}$ \\
\hline Acsl6 & 1.095921 \\
\hline$A l b$ & 1.13632 \\
\hline Ankrd34b & 1.468724 \\
\hline Apcs & 1.163418 \\
\hline Clqa & 0.4839 \\
\hline$C 2$ & 2.07736 \\
\hline$C b \ln 1$ & 1.11505 \\
\hline Chrdll & 0.97534 \\
\hline Cnrl & 1.3443 \\
\hline Cxcl11 & 0.58796 \\
\hline Dhx58 & 1.48114 \\
\hline Fam19a5 & 1.051074 \\
\hline Fbpl & 1.351329 \\
\hline Gsta3 & 1.20354 \\
\hline Ifi27 & 1.8479 \\
\hline Ifi44 & 0.50785 \\
\hline Krt15 & 1.338948 \\
\hline$M s 4 a 7$ & 0.76933 \\
\hline Mobp & 1.34379 \\
\hline Nefh & 1.289564 \\
\hline Neurodl & 1.755709 \\
\hline Olig1 & 0.9484 \\
\hline Parp14 & 0.18289 \\
\hline Pnlip & 1.11708 \\
\hline$R G D 1306880$ & 0.88192 \\
\hline$R G D 1560273$ & 1.09038 \\
\hline$R T 1-E C 2$ & 1.20744 \\
\hline Slc6al & 1.03796 \\
\hline Slc7a3 & 0.90495 \\
\hline Tmem 2 & 0.95757 \\
\hline
\end{tabular}

pathways has various effects, including promotion of cell death (12). Ifi44 potentially participates in GM-induced ototoxicity and nephrotoxicity by depleting intracellular GTP; however, how Ifi44 is upregulated by GM remains to be explored. Current research on Ifi44 has focused on its supporting role in the IFN signaling pathway, which is an important part of systemic lupus erythematosus diagnosis. However, the role of Ifi44 in ear and kidney injury is currently unclear.

GM may also affect the expression of connexin 26 in the cochlear lateral wall (17). Following GM administration, the expression of connexin 26 was increased over time (17). Interaction of connexin proteins with microtubules is essential to allow directed transport of newly synthesized connexin hemichannels to the plasma membrane (18). Considering its function, Ifi4 may also have a role in the increase of connexin 26 expression induced by GM.

In the present study, GM-induced ototoxicity and nephrotoxicity were confirmed by measurement of blood BUN and $\mathrm{SCr}$ levels. H\&E staining confirmed that inflammatory
Table V. Downregulated genes in the cochlear.

\begin{tabular}{|c|c|}
\hline Gene & $\begin{array}{c}\text { Difference value } \\
\text { (cochlear ratio-liver ratio) }\end{array}$ \\
\hline Actal & -1.147199 \\
\hline B3gnt5 & -0.605835 \\
\hline Bstl & -0.47024 \\
\hline Carl & -0.625612 \\
\hline Cox $8 b$ & -0.537492 \\
\hline Срох & -0.510466 \\
\hline Ctse & -0.611315 \\
\hline$D h f r$ & -0.647651 \\
\hline Eraf & -0.465653 \\
\hline Esml & -0.754375 \\
\hline Hemgn & -0.586487 \\
\hline Igh-6/LOC314509 & -0.619679 \\
\hline Klfl & -0.507804 \\
\hline LOC683399 & -0.633073 \\
\hline LOC687696 & -0.595911 \\
\hline$M b$ & -0.668166 \\
\hline Mcpt10/8/8l2/9 & -0.505066 \\
\hline Myh2/ Myh4 & -0.761466 \\
\hline Myll & -0.696605 \\
\hline Pcskl & -0.723895 \\
\hline Plek2 & -0.549672 \\
\hline Plunc & -0.792194 \\
\hline Rhd & -0.408416 \\
\hline Rrm2 & -0.341062 \\
\hline Slc22a4 & -0.45902 \\
\hline Sptal & -0.613168 \\
\hline Thbs4 & -0.642666 \\
\hline Tnnt3 & -0.466837 \\
\hline Tpm1 & -0.760636 \\
\hline Trak2 & -0.513582 \\
\hline
\end{tabular}

cells aggregated in the cochlear and kidney tissues following GM treatment. RT-qPCR and western blotting also demonstrated that Ifi44 was upregulated at the transcriptional and translational levels. Immunohistochemistry also demonstrated that at Ifi44 was upregulated in rat cochlear and kidney tissues following the GM treatment. The results suggested that Ifi44 has a connection to inflammations associated with GM-induced ototoxicity and nephrotoxicity.

Notably, other genes, including poly(ADP-ribose) polymerase family member 14 (Parp14), DExH-box helicase 58 (Dhx58), interferon $\alpha$ inducible protein 27 (Ifi27), membrane spanning 4-domains $A 7$ (Ms4a7), also exhibited similar expression changes in the kidneys and cochlear after GM administration. The role of such genes in the GM-induced ototoxicity and nephrotoxicity requires delineation in further studies.

In summary, the current study identified changes of the expression profiles in ear and kidney tissues following GM administration in rats. Investigation of Ifi44 gene expression in the cochlear and kidney tissues suggested that Ifi44 
Table VI. Genes upregulated in cochlear and kidney.

\begin{tabular}{|c|c|c|c|}
\hline Gene name (symbol) & Cochlear ratio & Kidney ratio & Liver ratio \\
\hline Complement Clq A chain (Clqa) & 2.23839 & 2.69487 & 1.75449 \\
\hline Complement C2 (C2) & 2.88087 & 2.46093 & 0.80351 \\
\hline$C-X-C$ motif chemokine ligand $11(C x c l 11)$ & 2.37037 & 16.2157 & 1.78241 \\
\hline DExH-box helicase 58 (Dhx58) & 4.23954 & 2.75184 & 1.94491 \\
\hline Interferon alpha inducible protein 27 (Ifi27) & 3.71297 & 2.00469 & 1.86291 \\
\hline Microtubule-associated protein 44 (Ifi44) & 2.45184 & 3.2915 & 1.944 \\
\hline Membrane spanning 4-domains A7 (Ms4a7) & 2.58608 & 4.65696 & 1.81675 \\
\hline Poly(ADP-ribose) polymerase family member 14 (Parp14) & 2.10233 & 2.81713 & 1.91944 \\
\hline RT1 class Ib, locus EC2 (RT1-EC2) & 2.54755 & 2.78453 & 1.34011 \\
\hline
\end{tabular}
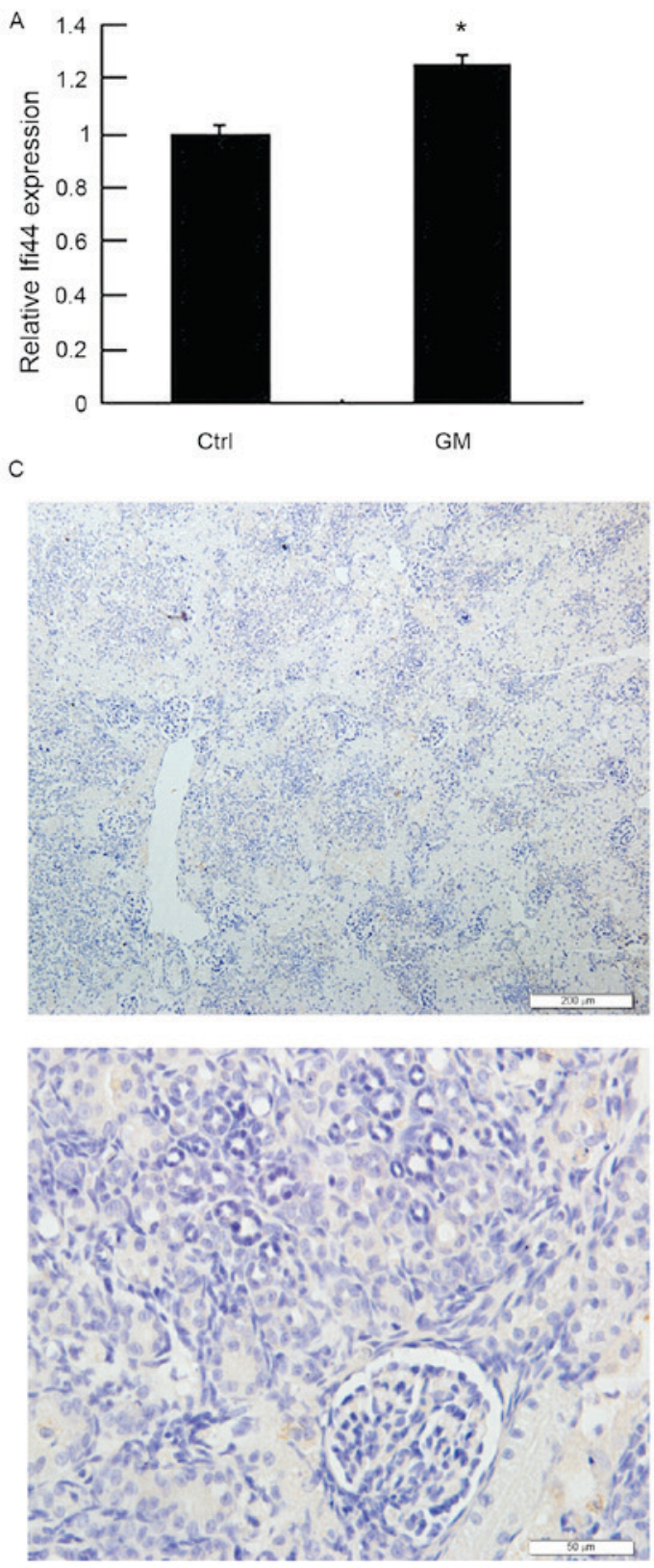

B
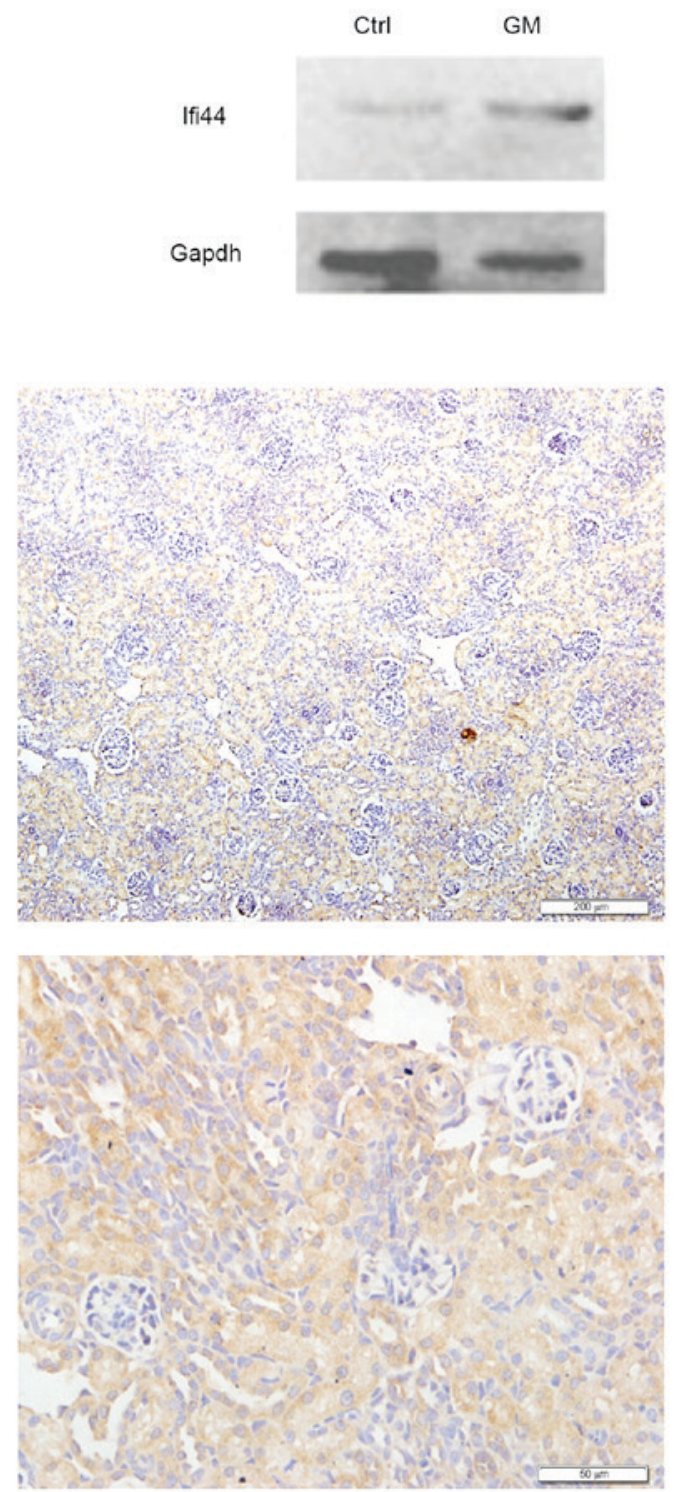

Figure 2. RT-qPCR, western blotting and immunohistochemistry analysis of Ifi44 expression in the kidney tissue. (A) RT-PCR analysis demonstrated significant upregulation of Ifi44 transcription in the GM group ( $\left.{ }^{*} \mathrm{P}<0.05\right)$. (B) Western blotting confirmed increased Ifi44 protein in the GM group. (C) Immunohistochemistry analysis also demonstrated upregulation of Ifi44 in the kidney tissue. Left panels, control group; right panels, GM group; upper panels, $200 \mu \mathrm{m}$ scale bar; bottom panels, $50 \mu \mathrm{m}$ scale bar. RT-qPCR, reverse transcription-quantitative polymerase reaction; Ctrl, control; GM, gentamicin; Ifi44, interferon-inducible protein 44. 
A

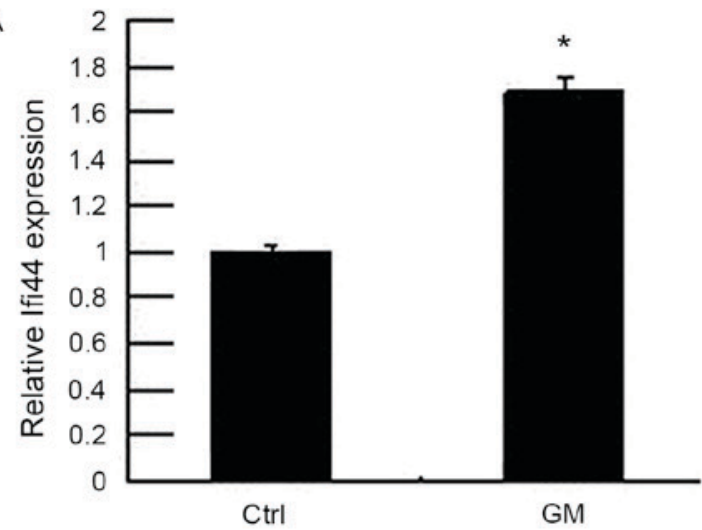

C
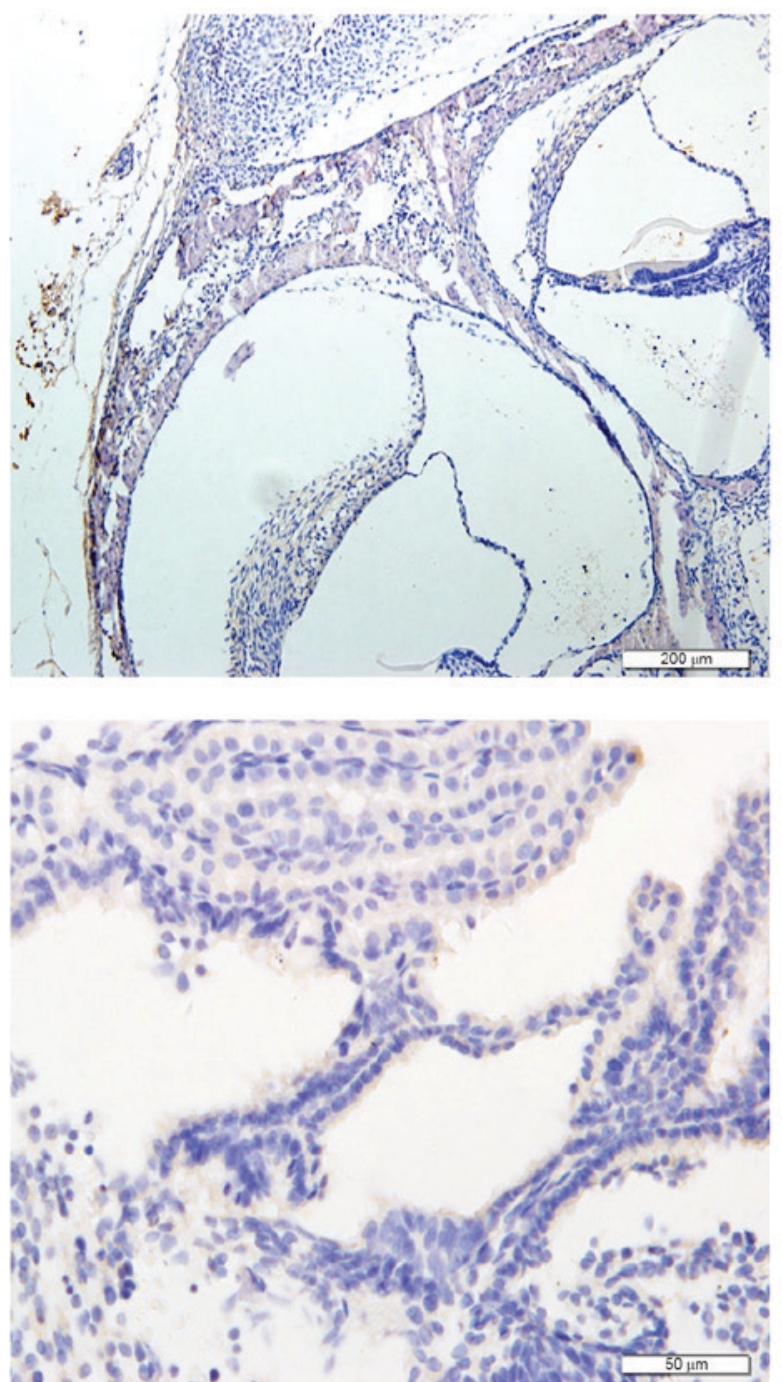

B
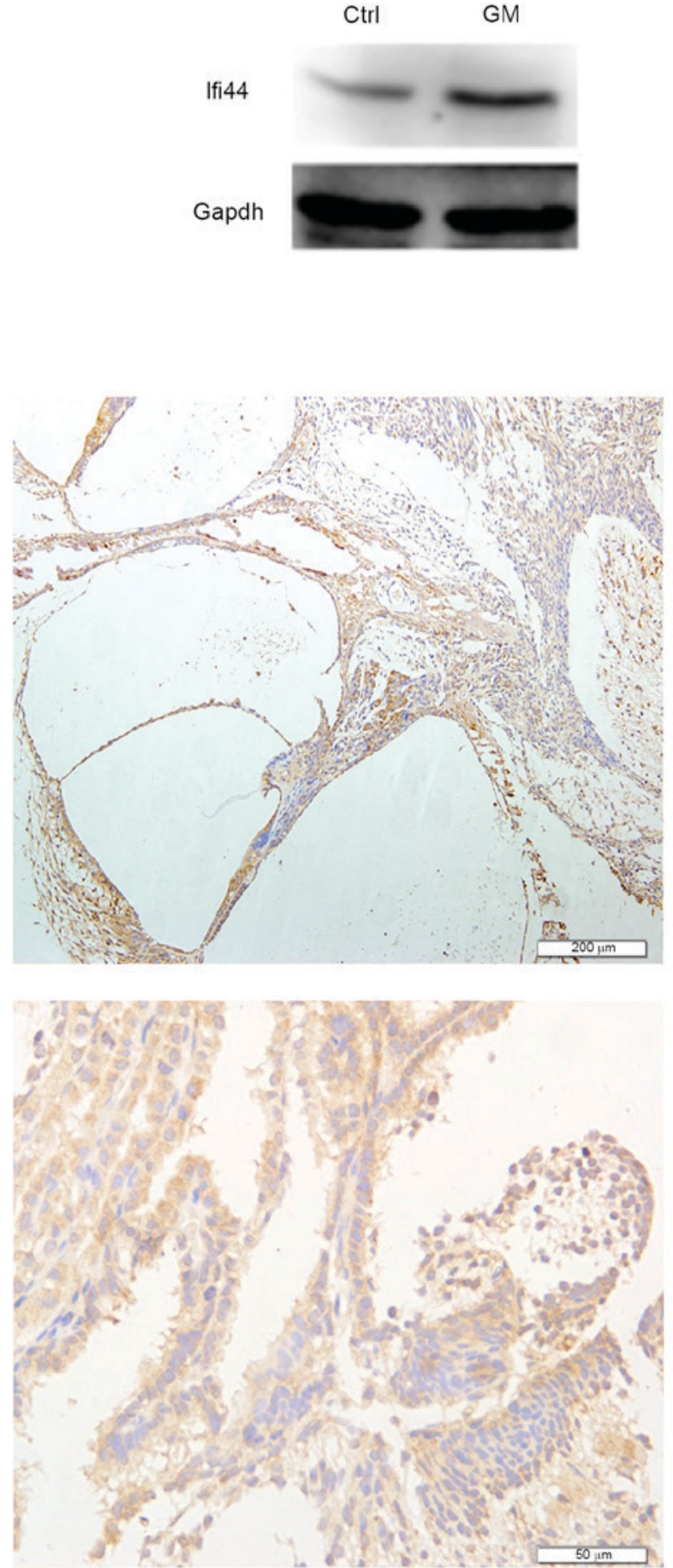

Figure 3. RT-qPCR, western blotting and immunohistochemistry analysis of Ifi44 expression in the kidney tissue. (A) RT-PCR analysis demonstrated significant upregulation of Ifi44 transcription in the GM group ("P<0.05). (B) Western blotting confirmed increased Ifi44 protein in the GM group. (C) Left panels, control group; right panels, GM group; upper panels, $200 \mu \mathrm{m}$ scale bar; bottom panels, $50 \mu \mathrm{m}$ scale bar. RT-qPCR, reverse transcription-quantitative polymerase reaction; Ctrl, control; GM, gentamicin; Ifi44, interferon-inducible protein 44.

may be associated with inflammation during GM-induced ototoxicity and nephrotoxicity. Despite the complex changes in the expression profile, the approach used in the present study may provide a strategy to systematically reveal signaling pathways that are shared by organs involved in specific diseases.

\section{Acknowledgements}

This work was supported by grants from the National Natural Science Foundation of China (grant nos. 81473446 and 81072899). 


\section{References}

1. Cuestas E, Bur C and Bongiovanni V: Mild external ear malformations and renal tract abnormalities: A meta-analysis. Rev Fac Cien Med Univ Nac Cordoba 63: 46-52, 2006.

2. Fu Y, Li F, Zhao DY, Zhang JS, Lv Y and Li-Ling J: Interaction between Tbx1 and Hoxd10 and connection with TGF $\beta$-BMP signal pathway during kidney development. Gene 536: 197-202, 2014

3. Lenoir M, Marot M and Uziel A: Comparative ototoxicity of four aminoglycosidic antibiotics during the critical period of cochlear development in the rat. A functional and structural study. Acta Otolaryngol Suppl 405: 1-16, 1983.

4. Vera-Roman J, Krishnakantha TP and Cuppage FE: Gentamicin nephrotoxicity in rats. I. Acute biochemical and ultrastructural effects. Lab Invest 33: 412-417, 1975.

5. Hashino E and Shero M: Endocytosis of aminoglycoside antibiotics in sensory hair cells. Brain Res 704: 135-140, 1995.

6. Hiel H, Schamel A, Erre JP, Hayashida T, Dulon D and Aran JM: Cellular and subcellular localization of tritiated gentamicin in the guinea pig cochlea following combined treatment with ethacrynic acid. Hear Res 57: 157-165, 1992.

7. Marcotti W, van Netten SM and Kros CJ: The aminoglycoside antibiotic dihydrostreptomycin rapidly enters mouse outer hair cells through the mechano-electrical transducer channels. J Physiol 567: 505-521, 2005.

8. Dai CF, Mangiardi D, Cotanche DA and Steyger PS: Uptake of fluorescent gentamicin by vertebrate sensory cells in vivo. Hear Res 213: 64-78, 2006.

9. Lang F, Vallon V, Knipper M and Wangemann P: Functional significance of channels and transporters expressed in the inner ear and kidney. Am J Physiol Cell Physiol 293: C1187-C1208, 2007.
10. Rodrigues FA, Prata MM, Oliveira IC, Alves NT, Freitas RE, Monteiro HS, Silva JA, Vieira PC, Viana DA, Libório AB and Havt A: Gingerol fraction from Zingiber officinale protects against gentamicin-induced nephrotoxicity. Antimicrob Agents Chemother 58: 1872-1878, 2014.

11. Rauch I, Müller M and Decker T: The regulation of inflammation by interferons and their STATs. JAKSTAT 2: e23820, 2013.

12. Hallen LC, Burki Y, Ebeling M, Broger C, Siegrist F, Oroszlan-Szovik K, Bohrmann B, Certa U and Foser S: Antiproliferative activity of the human IFN-alpha-inducible protein IFI44. J Interferon Cytokine Res 27: 675-680, 2007.

13. Mahoney JM, Taroni J, Martyanov V, Wood TA, Greene CS, Pioli PA, Hinchcliff ME and Whitfield ML: Systems level analysis of systemic sclerosis shows a network of immune and profibrotic pathways connected with genetic polymorphisms. PLoS Comput Biol 11: e1004005, 2015.

14. Pachiappan A, Thwin MM, Manikandan J and Gopalakrishnakone P: Glial inflammation and neurodegeneration induced by candoxin, a novel neurotoxin from Bungarus candidus venom: Global gene expression analysis using microarray. Toxicon 46: 883-899, 2005.

15. Livak KJ and Schmittgen TD: Analysis of relative gene expression data using real-time quantitative PCR and the 2(-Delta Delta C(T)) method. Methods 25: 402-408, 2001

16. Quiros Y, Vicente-Vicente L, Morales AI, López-Novoa JM and López-Hernández FJ: An integrative overview on the mechanisms underlying the renal tubular cytotoxicity of gentamicin. Toxicol Sci 119: 245-256, 2011.

17. Hu P, Lai R and Xie D: Gentamicin affects connexin 26 expression in the cochlear lateral wall. B-Ent 8: 77-84, 2012

18. Dbouk HA, Mroue RM, El-Sabban ME and Talhouk RS: Connexins: A myriad of functions extending beyond assembly of gap junction channels. Cell Commun Signal 7: 4, 2009. 